Вісник Дніпропетровського університету. Серія: геологія, географія. 2016. 24 (1), 120-124.

Vìsnik Dnìpropetrovs'kogo unìversitetu. Seriâ geologiâ, geographîa

Dnipropetrovsk University Bulletin. Series geology, geography. 2016, 24 (1), 120-124.

doi: $10.15421 / 111618$

http://geology-dnu.dp.ua

УДК $574+551.43$

\title{
Особенности формирования солевого состава почв на территории г. Днепропетровск
}

\author{
Л. А. Носова, В. В. Фундовая
}

Днепропетровский нацииональный университет имени Олеся Гончара, Днепропетровск, Украина, e-mail: nosova.lud@gmail.com; vfundovai@gmail.com.

Проведен геохимический мониторинг территории правого берега г. Днепропетровск за период 25.01.1982 - 31.05.1982 гг. Отобраны пробы грунтов из наблюдательных скважин и составлено их литологическое описание. Выполнен химический анализ образцов грунта. В результате обработки полученных данных рассчитаны токсичные соли, определены тип и степень засоления. Изучены закономерности распределения токсичных солей в почвенных отложениях на изучаемой территории. За время наблюдений установлено, что наиболее засоленные почвы расположены по ул. Мукачевская, ст. Диевка, ж/м Западный, пос. Мирный, парк Б. Хмельницкого, ул. Космическая.

Ключевые слова: геохимический мониторинг, химический анализ грунтов, токсичные соли, степень засоления

\section{Features of the formation of the salt composition in the soil on the territory of Dnepropetrovsk}

\author{
L. A. Nosova, V. V. Fundovaya \\ Oles Honchar Dnipropetrovsk National University, Dnipropetrovsk, Ukraine, \\ e-mail:nosova.lud@gmail.com; vfundovai@gmail.com.
}

Geochemical monitoring of the territory of the right bank of Dnepropetrovsk was performed in the period 01.25.1982 31.05.1982. Soil samples were selected from the observation wells and compiled their lithological description. The chemical analysis of soil samples was performed. As a result of the processing of the data calculated toxic salts, to determine the type and degree of salinity. Patterns of distribution of toxic salts were studied in soil deposits in the study area. It was found that the most saline soils during the period of monitoring are located on the st. Mukachevskaia, station Dievka, residential area Zapadnyi, settlement Mirnyi, park of B. Khmelnitskyi, str. Kosmycheskaia.

Key words: geochemical monitoring, chemical analysis of soil, toxic salts, degrees of salinity

Введение. Происхождение и свойства почвы неразрывно связаны с условиями окружающей среды. Она отражает в своих свойствах исторический ход влияющих на нее природных условий, а также техногенных факторов, связанных с деятельностью человека. В настоящее время проблема засоления почв приобретает все большее значение, как в условиях городов, так и в сельской местности. Техногенное загрязнение окружающей среды в городах носит комплексный характер. Происходит не только засоление почв, но и их загрязнение тяжелыми металлами, нефтепродуктами. Основная часть загрязняющих веществ поступает в городские почвы с атмосферными осадками, с мест складирования промышленных и бытовых отходов.

Естественный почвенный покров на большей части городских территорий уничтожен. Он сохра- нился лишь островками в городских лесопарках. Городские почвы (урбаноземы) различаются по характеру формирования (насыпные, перемешанные), по гумусированности, по степени нарушенности профиля, по количеству и составу включений (бетон, стекло, токсичные отходы) и т.д. Для большинства городских почв характерно отсутствие генетических горизонтов и наличие различных по окраске и мощности слоев искусственного происхождения. Особый вклад в ухудшение химических свойств почв городов вносят «снегоносы» - применение зимой солей в целях быстрого освобождения дорожных покрытий от снега. Для этого обычно используют хлористый натрий (поваренную соль), что ведет не только к коррозии подземных коммуникаций, но и к искусственному засолению почвенного слоя. В результате в городах и вдоль автомагистралей по- 
явились такие же засоленные почвы, как где-нибудь в сухих степях или на морских побережьях.

Ранее с явлениями, связанными с передвижением в грунтах солевых растворов, приходилось встречаться преимущественно при решении задач орошения земель. Однако вследствие развития масштабов подтопления застраиваемых территорий, где зачастую грунтовые воды при формировании становятся агрессивными, необходимо изучать их солевой режим, как и при решении задач, связанных со строительством зданий и сооружений.

Влияние соленосности грунтов как на их собственные строительные свойства, так и на устойчивость фундаментов зданий и сооружений, можно считать несомненным. Известно, что сопротивление сжатию, вязкость, текучесть, водные и фильтрационные свойства грунтов находятся в зависимости от количества заключающихся в грунте растворимых солей (Anpylov, 1976).

К засолённым относят такие почвы, которые содержат в своём генетическом профиле легкорастворимые соли в токсичных для сельского хозяйства количествах. Легкорастворимые соли, вызывающие угнетение и гибель растений, можно разделить на несколько групп.

1. Вредные легкорастворимые нейтральные соли. Они не обладают буферностью и дают рН чистых растворов 5,5 - 6,7; легко формируют опасные для фитоценозов концентрации. К этой группе солей относятся: хлориды ( $\mathrm{NaCl}$ - галит, $\mathrm{MgCl}_{2} \cdot 6 \mathrm{H}_{2} \mathrm{O}-$ бишофит), сульфаты $\left(\mathrm{Na}_{2} \mathrm{SO}_{4} \cdot 10 \mathrm{H}_{2} \mathrm{O}-\right.$ мирабилит, $\mathrm{Na}_{2} \mathrm{SO}_{4} \cdot 2 \mathrm{CaSO}_{4}$ - глауберит).

2. Вредные легкорастворимые гидролитические щелочные соли: способны создавать сильнощелочную среду. Широко распространены в щелочных горизонтах такие карбонаты как $\mathrm{NaHCO}_{3}$ - пищевая сода, $\mathrm{Na}_{2} \mathrm{CO}_{3} \cdot 10 \mathrm{H}_{2} \mathrm{O}$ - сода, которые обладают хорошей растворимостью и дают $\mathrm{pH} 9$; щелочность почвенного раствора повышают и малорастворимые карбонаты магния (например, $\mathrm{MgCO}_{3} \cdot \mathrm{Mg}(\mathrm{OH})_{2} \cdot 3 \mathrm{H}_{2} \mathrm{O}$ (магнезия) концентрируют раствор до рH 9,8) (Val'kov, Kazeev, Kolesnykov, 2004).

Кроме того, в почве могут содержаться безвредные соли: $\mathrm{CaCO}_{3}$ (кальцит), $\mathrm{CaSO}_{4} \cdot 2 \mathrm{H}_{2} \mathrm{O}$ (гипс) и бикарбонат кальция $\left(\mathrm{Ca}\left(\mathrm{HCO}_{3}\right)_{2}\right)$. Они не дают опасных концентраций, так как обладают малой растворимостью.

Цель работы. Оценка засоленности почвенных отложений отдельных районов на территории г. Днепропетровск.

Материал и методы исследования. Для изучения изменений солевого состава грунтов зоны аэрации на застроенных территориях объединением «Южукргеология» была пробурена 51 скважина на территории г. Днепропетровск (правый берег). Из них 48 скважин оборудованы для наблюдений за уровневым режимом и химическим составом грунтовых вод. С целью оценки засоленности пород были взяты данные водно-солевых вытяжек грунтов из отчета объединения «Южукргеология» за 1981 -1983 гг. г. Днепропетровск (Archakova, Podafa, Ostash, 1981 - 1983). Пробы грунта на водно-солевые вытяжки отбирались из 29 скважин, слагающих зону аэрации. Интервал отбора проб 0 - 0,1 м, 0,1 - 0,3 м, 0,3 - 0,5 м, 0,5-0,7 м, 0,7-1 м, 1-1,2 м, 1,2-1,5 м, 1,5-2 м и далее через 1 м. Всего было отобрано 454 пробы. Схематично на рисунке показано распределение наблюдательных скважин на исследуемой территории.

Выборка результатов состоит из 29 скважин. По каждой имеются данные о влажности грунта, величине $\mathrm{pH}$, минерализации, содержании катионов (кальций, магний, калий и натрий) и анионов (карбонаты, гидрокарбонаты, сульфаты, хлориды), типе и степени засоления, а также сумме токсичных солей и степени засоленности ними. Для каждой скважины рассчитано среднее содержание по зоне аэрации вышеперечисленных показателей.

Результаты и их анализ. Геологическое строение зоны аэрации рассматриваемых скважин представлено четвертичными отложениями. По литологическому составу данные скважины можно разделить на пять групп.

В первую группу входят скважины № 13, 14 . Генетические отложения представлены элювиальными, эолово-делювиальными отложениями. Зона аэрации сложена легкими суглинками с темно-серым, серовато-желтым, палево-желтым, буровато-серым цветом, тугопластичными, слабовлажными.

Скважины № 18 - 21, 24, 26, 28, 30 слагают вторую группу. Генетические отложения представлены элювиальными, эолово-делювиальными, делювиальными, техногенными отложениями. Литологически сложены средними суглинками с темно-серым, серовато-палевым, палево-желтым цветом, гумусированы, тугопластичны, слабовлажные, в верхних слоях с включением строительного мусора, кусков бетона, кирпича. Также редко встречаются карбонаты в виде прожилок.

Скважины № 17, 25, 31 - 34, 36, 38, 39, 50 составляют третью группу. Генетические отложения представлены элювиальными, эолово-делювиальными, делювиальными, техногенными отложениями. Зона аэрации сложена легкими и средними суглинками сероватого, палевого, серо-бурого, бурого, серо-ко- 


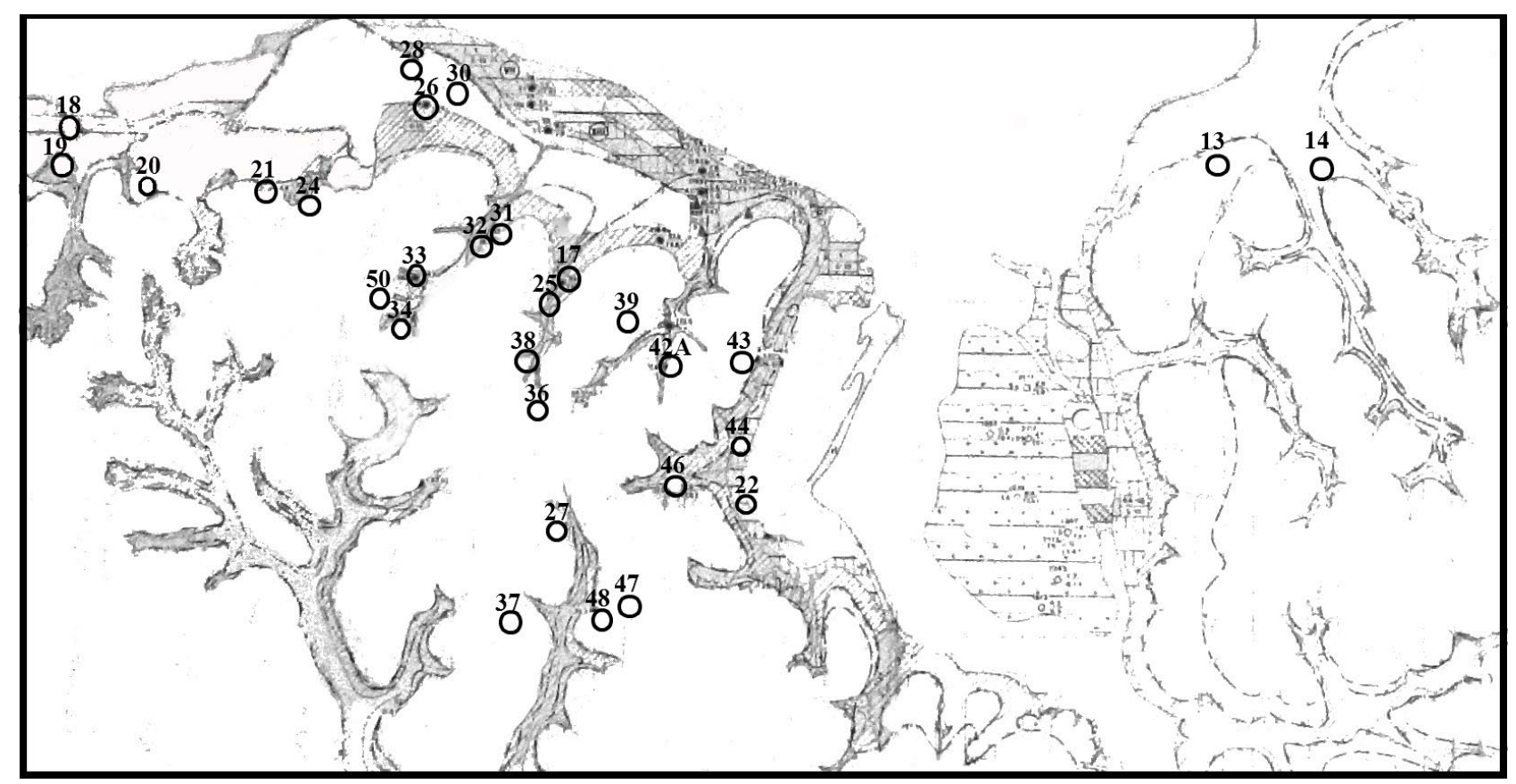

Рис. Распределение наблюдательных скважин на территории правого берега и ж/м Игрень г. Днепропетровск 26

Условные обозначения: $\mathrm{O}$ - гидрогеологическая скважина; сверху - номер скважины.

ричневого, буро-коричневого цвета, гумусированными, с включениями окислов марганца, железа, реже карбоната.

Скважины № 22, 27, 43, 44, 46 входят в четвертую группу. Генетические отложения представлены элювиальными, эолово-делювиальными, техногенными отложениями. Зона аэрации сложена легкими и средними суглинками сероватого, темно-серого, палево-серого, бурого цвета, с включением примазок карбонатов. Насыпной слой содержит строительный и бытовой мусор, куски бетона, кирпича.

Скважины № 47 и 48 составляют пятую группу. Генетические отложения представлены элювиальными, эолово-делювиальными, техногенными отложениями. Зона аэрации сложена легкими и средними суглинками палевого, желтого, желто-бурого, бурого, буро-коричневого цвета, с известковистыми включениями, реже макропористыми, слабовлажными карбонатами.

Посчитаны концентрации солей в каждой из исследуемых скважин. По основному солевому фону и близким концентрациям солей в зоне аэрации скважины были разбиты следующим образом.

В районе ж/м Игрень (скв. 13, 14) почвенный слой слабозасоленный, сумма токсичных солей колеблется в пределах 0,32 - 0,61\%. Основной солевой фон составляют соли гидрокарбонат кальция и магния. В скважинах № 13, 14 содержание гидрокарбонат кальция в зоне аэрации уменьшается с глубиной, а содержание гидрокарбонат магния возрастает. При распределении сульфат магния и кальция четкой зависимости не просматривается, и концентрация этих солей не превышает 20 \%. Концентрация хлорид натрия увеличивается по профилю с 12,5 до 22,5 \%. Хлорид магния встречается эпизодически и в незначительном количестве.

Почвенный слой района Диевки (скв. 18, 19, 20) среднезасоленный, сумма токсичных солей доходит до отметки 2,21\%. Основной солевой фон составляют соли сульфат кальция и гидрокарбонат кальция. В скважинах № 19, 20 содержание гидрокарбонат кальция в зоне аэрации уменьшается с глубиной, а содержание сульфат кальция возрастает. Распределение сульфат магния также имеет повсеместный закон, и его концентрация не превышает $30 \%$. Концентрация хлорид натрия уменьшается по профилю с 20 до 2 \%. Хлорид магния встречается эпизодически и в незначительном количестве, но в скважине 18 на глубине 6 м достигает концентрации 30 \%. Выявлено в зоне аэрации скважины № 20 наличие нитрат натрия (12,99\%) и нитрат магния $(7,26 \%)$.

В районе ж/м Западный (скв. 21, 24) почвенный слой в основном слабозасоленный, но в скважине 24 сумма токсичных солей в первом метре глубины доходит до отметки 2,12 \%. Основной солевой фон составляют соли сульфат кальция и гидрокарбонат кальция. При этом содержание гидрокарбонат 
кальция в зоне аэрации увеличивается с глубиной, а содержание сульфат кальция уменьшается. Распределение сульфат магния также имеет повсеместный закон, и его концентрация не превышает 29 \%. Концентрация хлорид натрия и сульфат натрия увеличивается по профилю с 6 до 17 \% и с 4,43 до 25,39\% соответственно.

В районе скважин № 26, 28, 30 почвенный слой слабозасоленный, сумма токсичных солей колеблется в пределах 0,34 - 0,93 \%. В скважине № 26 на глубине до 0,3 м токсичные соли составляют 1,21 $\%$. Основной солевой фон составляет гидрокарбонат кальция. При распределении сульфата магния и кальция четкой зависимости не просматривается, и концентрация этих солей не превышает 30 \%. Концентрация хлорид натрия уменьшается по профилю, максимальное значение составляет 33,77 \%, а минимальное $-6,58$ \%. Хлорид магния встречается эпизодически и в незначительном количестве.

В районе скважин № 31, 32 почвенный слой в основном слабозасоленный, но в скважине № 31 (ул. Канатная) сумма токсичных солей в первом метре глубины доходит до отметки 1,72 \%. Основной солевой фон составляет гидрокарбонат кальция. При распределении сульфат кальция и магния четкой зависимости не просматривается, но в отдельных пробах концентрация сульфат кальция достигает до 58,69 \%. С глубины 6 м выявлено наличие гидрокарбонат магния и натрия, соответственно концентрация первой соли уменьшается, а второй - возрастает и достигает 44,72 \%. Хлорид магния встречается эпизодически и в незначительном количестве. Концентрация хлорид натрия уменьшается по профилю с 1,21 до $26,5 \%$.

В районе скважин № 33, 34, 50 почвенный слой в основном слабозасоленный, но в скважине № 33 (ул. Мартеновская) сумма токсичных солей на глубине 10,5 м доходит до отметки 3,46 \%, что указывает на сильнозасоленный слой. Основной солевой фон составляют гидрокарбонат кальция и магния. В скважинах содержание гидрокарбонат кальция в зоне аэрации уменьшается с глубиной, а содержание гидрокарбонат магния возрастает. Распределение сульфат магния прослеживается до глубины 10 м, четкой зависимости не просматривается, концентрация достигает отметки 50,61 \% (скв. 33). Концентрация хлорид натрия увеличивается по профилю с 11,9 до 28,46 \%. Хлорид магния встречается эпизодически и в незначительном количестве.

В районе скважин № 36, 38 почвенный слой слабозасоленный, сумма токсичных солей колеблется в пределах 0,43 - 0,9 \%. В 36-й скважине (ул. Крас- нопольская) сумма токсичных солей достигает 2,1 \% до глубины 3 м. Основной солевой фон составляют сульфат кальция и магния и гидрокарбонат кальция, четкой зависимости не просматривается. Хлорид магния встречается эпизодически и в незначительном количестве. Концентрация хлорид натрия увеличивается по профилю с 26,72 до 12,42 \%.

В скважинах № 17, 25, 39 почвенный слой слабозасоленный, сумма токсичных солей колеблется в пределах 0,44-0,9 \%. В 17-й скважине (ул. Н. Руденко) сумма токсичных солей достигает 1,12\% на глубине до 0,3 м, а в скважине 39 (парк Б. Хмельницкого) - 2,16 \% на глубине 1 м. Основной солевой фон составляют сульфат кальция и гидрокарбонат кальция. С глубины 3 - 5 м возрастает концентрация гидрокарбонат магния до 26,97 \%. Распределение сульфат магния имеет повсеместный закон, и его концентрация в целом не превышает 30 \% (в нескольких пробах скважины № 39 достигает 40 \%). Концентрация хлорид натрия уменьшается по профилю с 22,13 до 3 \%. Выявлено в зоне аэрации скважины № 39 наличие нитрата натрия (43,19\%) и нитрата магния $(31,82 \%)$.

В скважинах № 37, 47, 48 почвенный слой в основном слабозасоленный. В нескольких пробах скважин № 37 и 48 сумма токсичных солей колеблется в пределах $1-1,6 \%$ и максимум ее составляет 2,78 \% (скв. 48, Тополь-2) на глубине 17,5 м. Основной солевой фон составляют гидрокарбонат кальция, гидрокарбонат натрия (из глубины 7 м в скв. 37 и 47) и сульфат натрия (скв. 48 из глубины 8 м). Концентрация хлорид натрия уменьшается по профилю с 18,5 до 6,3 \%. При распределении сульфат магния и гидрокарбонат магния четкой зависимости не просматривается, и концентрация этих солей не превышает 25 \%. Выявлено в зоне аэрации скважин № 37 (пос. Мирный) и № 47 (Тополь 1) наличие нитрат натрия $(24,29$ и $2,65 \%$ соответственно) и нитрат магния $(13,64 \%)$.

В скважинах № 22, 44, 46 почвенный слой - от слабо- до сильнозасоленного. Так, в скважине 22 на глубине 1 м сумма токсичных солей составляет 1,23\%. В скважине № 46 (ул. Космическая) в интервале глубины от 1 до 7 м сумма токсичных солей представлена от 1,04 до 5,16 \%. Основной солевой фон составляют гидрокарбонат кальция и сульфат кальция, последний из глубины 1 м. При распределении сульфат магния четкой зависимости не просматривается, и концентрация не превышает $28 \%$. Хлорид магния встречается эпизодически и в незначительном количестве. Концентрация хлорид натрия уменьшается по профилю с 14 до 8,11 \%. 
В скважине № 46 из глубины 4 м концентрация хлорид натрия возрастает до 54,09 \%. Выявлено в зоне аэрации скважины № 46 наличие нитрат натрия $(1,66 \%)$.

В скважинах 42A, 43 почвенный слой слабосреднезасоленный. Сумма токсических солей колеблется в пределах 0,27 - 1,34 \%. Основной солевой фон составляют гидрокарбонат кальция и магния, сульфат кальция (скв. 43). При распределении сульфат магния четкой зависимости не просматривается, и концентрация этих солей не превышает 19,85 \%. Хлорид магния встречается эпизодически и в незначительном количестве. Концентрация хлорид натрия увеличивается по профилю с 12,99 до 33,74 \%.

В районе скважины № 27 почвенный слой слабозасоленный, сумма токсичных солей колеблется в пределах 0,52 - 0,84 \%. Основной солевой фон составляют соли гидрокарбонат кальция, их концентрация уменьшается по профилю. При распределении сульфат магния и кальция четкой зависимости не просматривается, и концентрация этих солей не превышает 30 \%. Концентрация хлорид натрия увеличивается по профилю с 0,88 до 20,35 \%.

Выводы. В результате проведения геохимического мониторинга территории правобережной части г. Днепропетровск можно утверждать, что засоление токсичными солями зоны аэрации присутствует повсеместно. Почвенный слой классифицируется как слабозасоленный и среднезасоленный. В районе ж/м Игрень (скв. 13, 14) почвы содержат более $60 \%$ гидрокарбонат кальция и магния от общего количества солей, что может привести к повышению щелочности почвы. На отдельных участках ст. Диевка (скв. 20), пос. Мирный (скв. 37), парк Б. Хмельницкого (скв. 39), ул. Космическая (скв. 46), Тополь-1 (скв. 47) наблюдается локальное загрязнение почвы азотистокислыми солями магния и натрия, что свидетельствует о поступлении солей с хозяйственно-бытовыми и сточными водами.
Среднезасоленные почвы находятся в пределах участков ст. Диевка (скв. 18, 19, 20), ул. Кропивницкого (скв. 24), просп. С. Нигояна (скв. 26), ул. Канатная (скв. 31), ул. Краснопольская (скв. 36), парк Б. Хмельницкого (скв. 39), Тополь-2 (скв. 48), пос. Мирный (скв. 37), ул. Космическая (скв. 46), ул. Победная (скв. 43). Сильнозасоленные почвы выявлены на участках ул. Мартеновская (скв. 33) и ул. Космическая (скв. 46).

Необходимо контролировать уровень солесодержания в грунте территории города, так как существенное влияние засоленность оказывает на процессы коррозии и суффозии. Также при озеленении районов нужно учитывать уровень солей в грунтах.

\section{Библиографические ссылки}

Anpylov, V.E. 1976. Formyrovanye y prognoz rezhyma gruntovyyh vod na zastrayvaemyyh terrytoryjah [Formation and forecast of groundwater regime in the built-up areas]. Moscow, Nedra, 184 (in Russian).

Archakova, E.G., Podafa, V.A., Ostash, E.S. 19811983. Otchet o rezul'tatah rabot po yzuchenyju эkzogennyyh geologycheskyh processov na terrytoryy g. Dnepropetrovska [Report on the results of studies on the exogenous geological processes on the territory of Dnepropetrovsk]. Yuzhukrgeologiya, Novomoskovsk GRE, Dnepropetrovsk (in Russian).

Val'kov, V.F., Kazeev, K.Sh., Kolesnykov, S.Y. 2004. Zasolenye pochv. Vtorychnoe zasolenye [Salting of soils. Secondary salinization]. Soil science: the textbook for universities. Rostov-on-Don, Publishing Center MarT, 475 (in Russian).

Kovda, V.A. 1946. Proyshozhdenye y rezhym zasolennyyh pochv. Tom I [Origin and condition of saline soils. Tom I]. Moscow, Publishing House of the USSR Academy of Sciences, 574 (in Russian).

Novykova, A.V. 2009. Yssledovanyja zasolennyyh y soloncovyyh pochv. Genezys, melyoracyja, ekologyja [Research of saline and alkaline soils. Genesis, amelioration, ecology]. Kharkiv, 740 (in Russian). 